\title{
The buzz about pollination
}

Peter D. Moore

A PUZZLE for pollination ecologists has been explaining the advantages of the structure of certain types of flower, such as some nightshades (including potato), which have reflexed petals, and stamens that form a projecting conical mass as shown in the photograph. One suggestion is that visiting bees cause pollen-shedding by buzz-pollination (sonication pollendispensing to the purist), so keeping the petals out of the way is a means of reducing their potential damping of the vibrations. But such a proposal leaves many questions unanswered - what, for instance, is the frequency required for pollen release, and how does the flower avoid shedding its entire load of pollen when stimulated?

These issues have been investigated by M. J. King and S. L. Buchmann ${ }^{1}$, and their conclusions are reported in Functional Ecology. The key, they feel, is not in the buzz frequency, but in the force that the bees can exert on the pollen-containing heads of stamens, the anthers, by accelerating their vibrations and throwing the pollen out of the exit pore.

Buzz-pollination is an appealing but not strictly accurate term given to a system of pollen collecting (rather than pollen depositing, as implied by 'pollination') associated with certain bumble-bees (Bombus spp.). These bees are able to uncouple their wing movements from the actual mechanism of flight and can vibrate them, as when warming-up before flight and when communicating by sound ${ }^{2}$. They may also perform this exercise when foraging from certain types of flower, including some of the nightshade family (Solanaceae), some Primulaceae, some heaths (Ericaceae), Boraginaceae and various others.

These flowers have several characteristics in common. They often provide a reward of only pollen for the visiting bee; they usually have bent-back petals revealing a conically arranged series of anthers (sometimes brightly coloured); and the anthers release their pollen through an apical pore, in a salt-cellar fashion. The flowers are also normally pendent and typically have very small pollen grains (less than $25 \mu \mathrm{m}$ ).

According to Barth ${ }^{3}$, buzz-pollination was first recorded in 1959 by John H. Barrett in the highlands of New Guinea, when he noticed low-frequency buzzing sounds coming from foraging bees in the forest, and it has subsequently been observed in many plants in virtually all climatic zones. Pollination ecology is a particularly fertile field for the study of co-evolution and the biophysics of buzz-pollination has presented some intriguing challenges. What is the most effective frequency of vibration for pollen release? Does this correspond to the natural frequency of the flower? Is this the frequency operated by the visiting bee?

Working on the North American buzzpollinated member of the Primulaceae, the shooting-star (Dodecatheon conjugens), Harder and Barclay ${ }^{4}$ found that vibrations of $400 \mathrm{~Hz}$ and below (the

\section{IMAGE UNAVAILABLE FOR COPYRIGHT REASONS}

Design for giving - the structure of the flower of the potato, Solanum tuberosum, lends itself to pollendispensation by sonication by visiting bees.

frequency used by bumble-bees) resulted in less than $10 \%$ of the available pollen being released, whereas higher frequencies liberated over $23 \%$ of the pollen. Their explanation of the difference was that the higher tuning frequency of the flower ensured that a visiting bee did not take away too high a proportion of the pollen - the equivalent, for the flower, of not placing all of one's eggs in one basket.

The story, however, has not proved so simple and some workers have found no relationship between frequency and pollen liberation; others have proposed that a gradual drying of the pollen may regulate the release ${ }^{5}$. In an attempt to clarify the situation, King and Buchmann $^{1}$ have turned to a New Zealand nightshade, the poroporo (Solanum laciniatum), and have examined not only frequency effects, but also the role of accelerating frequency in stimulating pollen shedding. Their argument is that, because force is equal to mass times acceleration, a low-frequency vibration with rapid acceleration can generate a high pollen-releasing force.

Flowers that were ripe but had not shed their pollen were found to have natural frequencies of $195 \mathrm{~Hz}$, which became lower following dehiscence of the anthers. Foraging Bombus bees were observed to apply buzz frequencies of around $300 \mathrm{~Hz}$ to the Solanum flowers and generated vibration accelerations of about $180 \mathrm{~m} \mathrm{~s}^{-1}$, which were sufficient to cause pollen ejection (the minimum acceleration required was $105 \mathrm{~m} \mathrm{~s}^{-1}$ ). So the force applied by the bee to this flower is adequate for the purpose and the plant is not economizing on pollen by being tuned to a higher frequency.

$\bar{\Phi}$ The initial sonication, however, released only $18 \%$ of the available pollen, but this was still a rel平 atively large load (about 72,000 pollen grains). Yet the flower still retains a significant proportion of its pollen production for future visitors. King and Buchmann suggest that this is being achieved by a gradual drying process within the tissues of the anther so that more pollen grains are made available for sonication at the next visit. This ensures that pollen is dispensed from a particular anther over a period of time, thus increasing the dispersal potential of the grains and the likelihood of success in widespread pollination. The bees are evidently aware of these limitations to the success of vibration-induced pollen harvesting because they commence their foraging with a low-magnitude buzz to check that the flower is in a position to respond to more intense sonication before further energy is expended on that activity. The need for dryness in the pollen prior to sonication may also explain the recurved petals and the pendent habit of many buzz-pollinated flowers.

The efficiency of the buzz in persuading an anther to part with a proportion of its pollen load makes one wonder how widespread this phenomenon may be, especially among flowers equipped with anthers that open through a terminal pore. Giving it a quick shake seems such an obvious answer to many a bee's problems.

Peter D. Moore is in the Division of Life Sciences, King's College London, Campden Hill Road, London W8 7AH, UK.

\footnotetext{
1. King, M. J. \& Buchmann, S. L. Funct. Ecol. 10, 449-456 (1996).

2. Proctor, M., Yeo, P. \& Lack, A. The Natural History of Pollination (Collins, London, 1996)

3. Barth, F. G. Insects and Flowers: The Biology of a Partnership (Princeton Univ. Press, 1985).

4. Harder, L. D. \& Barclay, R. M. R. Funct. Ecol. 8 , 509-517 (1994).

5. King, M. J. \& Ferguson, A. M. Ann. Bot. 74, 479-482 (1994).
} 